\title{
Contrasting patterns of species and functional composition of coral reef sponge assemblages
}

\author{
James J. Bell* \\ Victoria University of Wellington, School of Biological Sciences, PO Box 600, Wellington, New Zealand
}

\begin{abstract}
There is mounting interest in studying the relationship between functional (FD) and species diversity (SD) in order to understand ecosystem functioning and develop effective measures to protect communities. Several studies have found strong positive correlations between SD and FD and in this study I used sponges to investigate this relationship and compare it with that of functional and species composition (FC and SC respectively). This study was conducted at 2 coral reef ecosystems in SE Sulawesi, Indonesia, which experience different sedimentation levels. Sponges fulfil a number of key functional roles on coral reefs, and, as many can be associated with specific morphologies, the measurement of morphological diversity (MD) should provide an approximation of FD. Previous sponge research has shown a strong correlation between MD and SD, and I hypothesise that spatial variation in MD, FD, SD and assemblage composition (FC and SC) will be determined by the same environmental gradients. Univariate measures of SD, MD and FD showed strong correlations, but not for multivariate data. Although different morphological assemblages (MC) were found at the 2 sites and between depth intervals, which correlated with SC data, no significant correlation was reported with FC data. FC was strongly influenced by depth, but not site, demonstrating that factors attributable to depth (e.g. light and wave action reduction) were more important in controlling FC, which contrasts with SC and MC patterns that were determined by sedimentation levels (i.e. between site differences). Although sponges fulfilled several functional roles, most were performed by a large number of morphologies/species, indicating a high level of intra-phyletic functional redundancy. The data from this study asserts that the factors responsible for spatial variation in SC may not always reflect those responsible for FC patterns, which has widespread implications for marine conservation, environmental management and Marine Protected Area (MPA) ecology. Environmental managers need to be aware of the factors controlling both SC and FC to ensure the protection of both biodiversity and ecosystem functioning.
\end{abstract}

KEY WORDS: Sponge · Morphology · Functional diversity · Ecosystem functioning · Functional composition · Diversity · Functional redundancy · Conservation - Marine Protected Areas (MPA)

\section{INTRODUCTION}

During the past decade interest has grown in ecosystem functional diversity (FD) and its relationship to species diversity (SD), ecosystem functioning and extinction (Petchey \& Gaston 2002a,b, 2006). Despite this widening interest, most research has focused on terrestrial ecosystems, with fewer studies having been conducted in marine environments (but see Steele 1991, Bremner et al. 2003, Micheli \& Halpern 2005). Furthermore, there is a paucity of data detailing the physical and biological processes influencing temporal and spatial variability in FD; however, research showing strong correlations between SD and FD (e.g. Micheli \& Halpern 2005) supports the hypothesis that such processes affect SD and FD in a similar manner. Understanding these relationships is vital from both a conservation and management perspective to ensure that ecosystem functioning and species diversity are protected, because the protection of one may not necessarily ensure the survival of the other. It is particularly important in marine conservation to understand 
factors controlling FD and SD at local levels, since this is commonly the scale on which conservation efforts are focused. There has been some debate over the most suitable way to measure FD and those species traits that should be used for FD characterisation (Petchy \& Gaston 2006). Classification schemes that are based on trophic levels or energy assimilation mechanisms (e.g. Naeem 2002, Petchey \& Gaston 2006) may potentially overlook important functions unrelated to these processes (Bremner et al. 2003). Furthermore, research on the relationship between FD and SD has mainly compared univariate measures, with little consideration for multivariate measures of functional composition (FC) of assemblages or communities, which may not necessarily reflect univariate patterns (see Bremner et al. 2003).

Sponges can be considered a model taxon with which to investigate numerous ecological processes and theories as they are widespread and abundant across temperate, tropical and polar regions (e.g. Dayton et al. 1974, Bell \& Barnes 2000a, Bell \& Smith 2004). Sponges are important benthic community members, and variation in their abundance, diversity and distribution will influence other benthic organisms and ecosystem characteristics through their superior competitive ability (Aerts \& van Soest 1997, Bell \& Barnes 2003) and biomass dominance (Wilkinson 1987). The functional and ecological roles of sponges on coral reefs are diverse because they occupy key roles in spatial competition, bio-erosion, reef consolidation/ stabilisation (including mineralisation and cementation), disruption of near substratum flow regimes (and boundary layers), nutrient recycling/water filtering, primary production and nitrogen flux, while also acting as microhabitats (Wulff 2001, 2006). Many of the roles sponges play in reef dynamics can be associated with specific sponge morphologies. For example, boring/burrowing sponges are primarily involved in bioerosion (Pang 1973, Rützler 1975), while encrusting sponges are more important in reef consolidation (Wulff \& Buss 1979) because they occupy large areas of the substratum (Aerts \& van Soest 1997, Bell \& Smith 2004) and can grow between coral stabilising the substrate (Wulff \& Buss 1979). The primary role of most sponges is filtering water/nutrient recycling and, although all sponges will contribute to this functional role to some extent, larger specimens will filter greater volumes of water than more cryptic or smaller forms. Three-dimensional sponge morphologies will have greater influence on the near-benthos flow regime and aid in reducing near-boundary layer current flow depletion (Hiscock 1983) compared with low profile forms. Such changes in micro- and macro-scale flow regimes by flow interruption can have major consequences for the downstream feeding success of other organisms (Okamura 1985). As sponges are one of the top spatial competitors (Bell \& Barnes 2003, J. Bell unpubl. data) they will be involved in the creation of space. Even though sponges can overgrow corals (Aerts \& van Soest 1997), they are probably prevented from reaching spatial dominance because they are more susceptible to physical disturbance (Wulff 1995). This functional role is primarily fulfilled by low profile forms that occupy larger areas of the benthos per unit volume, compared with upright forms where growth predominates away from the substratum. Finally, sponges can be considered important microhabitats because a large number of organisms have been associated with sponges, including diatoms, molluscs, crustaceans, echinoderms and fish (Koukouras et al. 1996), with massive morphologies supporting high biological diversity.

There are many studies quantifying sponge species diversity (including Dayton 1978, Hiscock 1983, Bell \& Barnes 2000a, Bell \& Smith 2004), but no attempt (but see Wulff 2001) to quantify FD; nevertheless, the role of individual species or families has been considered in some cases (e.g. boring sponges; Pang 1973, Rützler 1975). The local-scale factors that influence sponge biodiversity and abundance have been well described and include light, temperature, extreme storm events, substrate type, turbulence, sedimentation, nutrient levels and depth (Reiswig 1971, Wilkinson 1987, Alcolado 1990, Schmahl 1990, Cheshire \& Wilkinson 1991, Wulff 1995, Barnes 1999, Barnes \& Bell 2002, Carballo 2006), with many of these factors also being reported to influence sponge morphologies (e.g. Burton 1947, Palumbi 1984, Bell \& Barnes 2000a, Bell et al. 2002, Bell 2004). How these factors influence FD and whether patterns observed reflect those reported to control SD and morphological diversity (MD) remains unknown. In addition to the functional roles played by different sponge morphologies, many are also considered adaptive to specific environmental regimes (Bell \& Barnes 2000a). If certain sponge morphologies are restricted to specific habitats then they may only fulfil their functional roles in particular environmental conditions.

A relationship between sponge SD and MD has been described at a number of temperate and tropical localities (Bell \& Barnes 2001, 2002, Bell et al. 2006), including the location of the present study, which focuses on 2 coral reef systems experiencing different sedimentation regimes (low levels of natural coarse-grained vs. high levels of fine-grained sediment) in SE Sulawesi, Indonesia. Sponge SD is thought to be strongly influenced by sedimentation at these 2 sites (Bell \& Smith 2004) and, given the relationship between SD and MD, it follows that if MD is a suitable measure of FD then all 3 should be influenced by sedimentation in a similar way; therefore, in this study I tested the following 
hypotheses: (1) sponge MD is a suitable measure of $\mathrm{FD}_{\text {; }}(2)$ changes in sponge $\mathrm{SD}$ and MD in response to sedimentation are the same as those reported in FD; (3) there will be no difference in the effect of environmental gradients on the $\mathrm{FC}, \mathrm{SC}$ and morphological composition (MC) of sponge assemblages. To test these hypotheses, sponge morphological data was collected along 2 sedimentation gradients, firstly between sites experiencing different sedimentation regimes and secondly with depth. These data were used to determine FD and FC, which were compared with species data (from Bell \& Smith 2004).

\section{MATERIALS AND METHODS}

Study site. Sponge assemblages were sampled at 2 sites in the vicinity of Kaladupa in SE Sulawesi, Indonesia (for site locations see Bell \& Smith 2004). These 2 sites have different gross sedimentation rates and sediment composition (grain size), with more fine particles settling from suspension at Sampela compared with Hoga, which experiences low levels of coarse sedimentation. The sediment accumulation rates are also different between the 2 sites, with a layer of sediment $(<5 \mathrm{~mm}$ thick) covering surfaces at Sampela, while surfaces are generally devoid of sediment at Hoga. Sampela is an impacted coral reef ecosystem owing to fishing activities, coral mining and sedimentation (to date it is unclear if the sediment is from anthropogenic or natural sources). Since the settling sediment particle size is much smaller at Sampela, sediment particles remain in the water column longer, increasing turbidity and reducing light penetration, while the larger particles at Hoga quickly settle from suspension.

Collection of species and morphological data. At each site, ten $0.5 \times 0.5 \mathrm{~m}$ arbitrary (within surface types available) quadrats were taken on vertical $\left(90^{\circ}\right)$, inclined $\left(45^{\circ}\right)$ and horizontal $\left(0^{\circ}\right)$ reef surfaces to collect species and morphological data. Sampling took place on the reef flat $(0 \mathrm{~m})$ and at 5, 10 and $15 \mathrm{~m}$ depth (exclusively at the Hoga site, because the reef at Sampela only extends to 11 to $13 \mathrm{~m}$ ). No sampling was conducted below $15 \mathrm{~m}$ owing to local diving safety regulations. Within each quadrat the total numbers of each sponge morphology (number of patches/distinct sponges) or species, as appropriate, were recorded. Morphological and species data were collected independently of each other within the same 3 wk study period during July 2002 (see Bell \& Smith 2004 for species data).

Data analysis. Patterns of $\mathrm{MD}$ and $\mathrm{SD}\left(H^{\prime}\right)$ were described with the Shannon and Wiener information function $\left(\log\right.$ e),$H^{\prime}=-\Sigma p_{i} \times \ln p_{i}$, where $p_{i}$ is the portion of each morphology or species in the assemblage (calculated from all data averaged across the 10 quadrats). Species richness was expressed as the total number (sum) of species or morphologies reported across the 10 quadrats at each site/depth/surface angle combination. For multivariate analysis, sponge morphological and species data from each site and depth was $\log (x+1)$ transformed prior to ordination by nonmetric multi-dimensional scaling (nMDS) to reduce the importance of rare species (MDS in Plymouth Routines in Multivariate Ecological Research [PRIMER]). This analysis was undertaken on a similarity matrix, created from Bray-Curtis similarity analysis, to ascertain any similarity or differences between sites, and among depths and surface angles. The RELATE function in PRIMER was used to compare the similarity matrices produced from Bray-Curtis similarity analysis.

Functional classification scheme. A proposed scheme of the functional roles of sponge morphologies was constructed by placing each sponge morphology into 1 or more of the following groups, based on the function of their shape rather than species identity: (1) filtering/ nutrient recyclers, (2) reef consolidators/stabilisers, (3) major spatial competitors, (4) disruptors of nearsubstratum water flow regimes (including boundary layer), (5) bio-eroders, (6) microhabitat providers and (7) primary producers. This classification scheme is based on a combination of trophic and biological traits of sponge morphologies (see Bremner et al. 2003, Petchey \& Gaston 2006), from observations of sponges of the region (Functions 2, 3, 4 \& 6) and the literature (Functions $1 \& 5$ ). This abundance information was presented as the proportion of sponges fulfilling each of these roles, which was then treated in the same way as species and morphological data. The presence/ absence of photosynthetic symbionts (Function 7) in the sponge morphologies was assessed using underwater pulse amplitude modulated (PAM) fluorometry (Diving PAM).

\section{RESULTS}

\section{Diversity and richness}

In total, 39 distinct morphological groups were identified in the study area, representing 39 sponge families and approximately 100 species (Tables 1 \& 2). Different patterns of morphological and species richness were observed between depth intervals, while little difference was evident among surface angles or between the 2 sites (Fig. 1). At Sampela and Hoga, morphological and species richness increased with depth between the reef crest and $10 \mathrm{~m}$. At Hoga, approximately the same morphological and species richness was recorded at 10 and $15 \mathrm{~m}$ (for each vari- 
Table 1. Number of species from different sponge families reported at 2 sites in SE Sulawesi, Indonesia. The morphologies found in each family are also shown (for definition, see Table 2)

\begin{tabular}{|c|c|c|c|}
\hline Family & Sampela & Hoga & $\begin{array}{l}\text { Morphologies } \\
\text { exhibited }\end{array}$ \\
\hline Ancorinidae & 1 & 3 & $15,31,37,38$ \\
\hline Agelasidae & 2 & 2 & $21,23,27,36$ \\
\hline Aplysinidae & 1 & 2 & 18,24 \\
\hline Axinellidae & 1 & 2 & $27,11,36$ \\
\hline Callyspongiidae & 0 & 3 & $5,17,14,34,35,36$ \\
\hline Chalinidae & 2 & 1 & $6,14,38$ \\
\hline Chondrillidae & 2 & 2 & $6,18,19$ \\
\hline Clathrinida & 0 & 3 & 4,26 \\
\hline Clionaidae & 0 & 3 & 3,8 \\
\hline Coelosphaeridae & 0 & 2 & 6,38 \\
\hline Desmacellidae & 3 & 4 & $18,36,38$ \\
\hline Dictyonellidae & 4 & 2 & $6,11,19$ \\
\hline Dysideidae & 3 & 4 & $12,13,14,16,18,38,39$ \\
\hline Geodiidae & 1 & 0 & 15 \\
\hline Halichondriidae & 2 & 3 & $10,18,19,38$ \\
\hline Hymedesmiidae & 3 & 1 & $29,36,38$ \\
\hline Hymeniacidonidae & 1 & 2 & 38 \\
\hline Ianthellidae & 2 & 2 & 18,28 \\
\hline Irciniidae & 2 & 3 & $14,15,18$ \\
\hline Isodictyidae & 1 & 1 & 2 \\
\hline Microcionidae & 4 & 6 & $11,27,38$ \\
\hline Mycalidae & 1 & 1 & 38 \\
\hline Neopeltidae & 1 & 1 & 22 \\
\hline Niphatidae & 3 & 3 & $9,10,11,34,35,36,38$ \\
\hline Petrosidae & 1 & 2 & $1,17,30,36$ \\
\hline Placospongiidae & 1 & 0 & 38 \\
\hline Plakinidae & 2 & 2 & $32,33,38$ \\
\hline Phloeodictyidae & 1 & 1 & $7,23,24,25$ \\
\hline Podospongiidae & 1 & 1 & 27 \\
\hline Raspailiidae & 1 & 3 & $6,11,38$ \\
\hline Spirastrellidae & 2 & 2 & 3,38 \\
\hline Spongiidae & 1 & 1 & 11 \\
\hline Suberitidae & 4 & 3 & $6,18,19,22,25,38$ \\
\hline Tedaniidae & 0 & 2 & 38 \\
\hline Tethyidae & 1 & 2 & 6,15 \\
\hline Tetillidae & 0 & 2 & 15 \\
\hline Thorectidae & 2 & 2 & $22,23,24,38$ \\
\hline Timeidae & 1 & 1 & 38 \\
\hline
\end{tabular}

able independently). At both sites, for any specific depth interval, there were no differences in species or morphological richness between sites. Comparisons between species and morphological richness showed similar patterns with increasing depth at both sites and between sites, with the only difference being the greater species richness found on vertical than on inclined and horizontal surfaces, respectively, at Sampela. No such pattern was reported for morphological data at either site. The same general patterns reported for species richness were also found for ShannonWiener diversity indices (Fig. 1).

Although morphological richness was high, only a few morphologies dominated the reef surfaces (Table 2). The most common sponge morphologies found were flakes, encrusting and flake-digitate forms. These 3 morphologies were common on all surfaces sampled, but were particularly prevalent on the reef flat at both sites (mainly Dysidea herbacea). The majority of morphologies constituted $<1 \%$ of the total sponges reported, while only a few morphologies were characteristic of any specific site/depth combination. There were some differences between sites (Table 2); for example horizontal plates, massive crusts and cushions were all more abundant at Hoga than Sampela, while flake forms predominated at Sampela.

\section{Sponge functional diversity}

All morphologies had at least 2 functional roles, because all sponges are involved in filtering/nutrient recycling to some extent. Investigation of the proportion of sponges fulfilling each functional role found
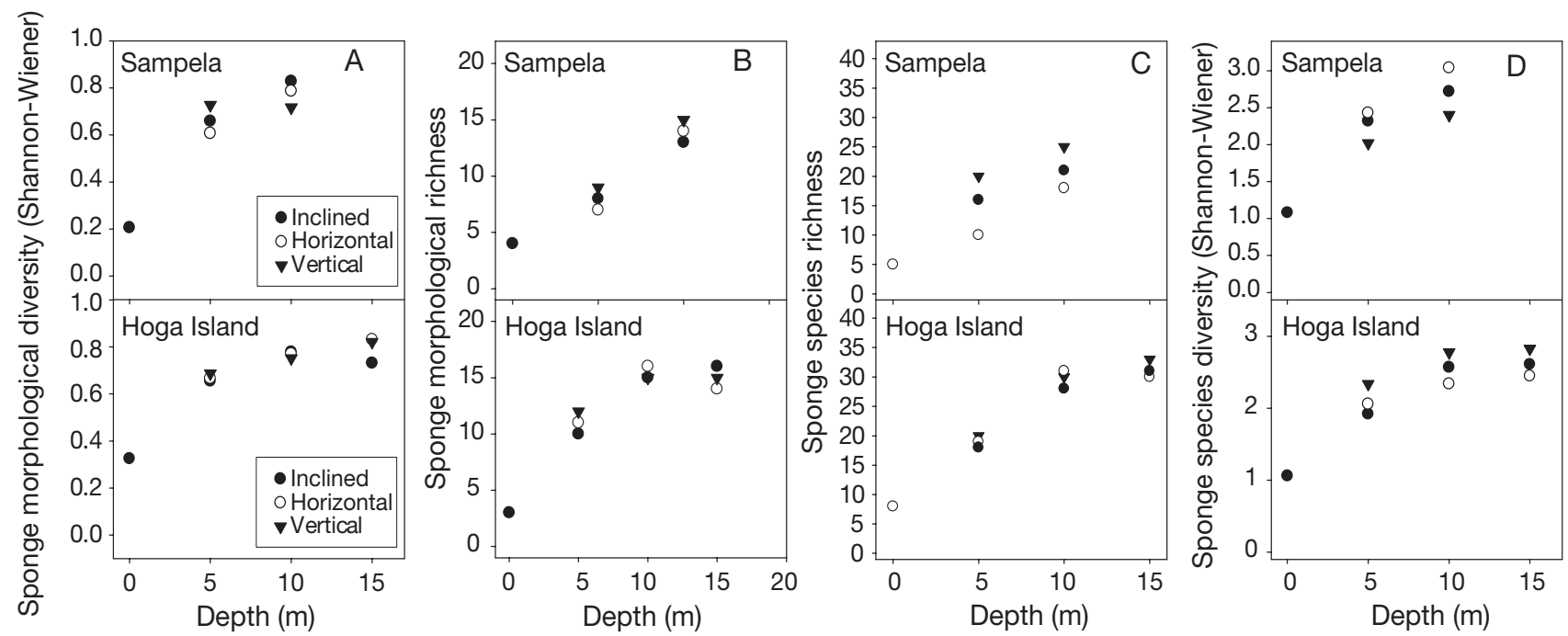

Fig. 1. Changes in (A) sponge morphological richness (total no. of morphologies), (B) sponge morphological diversity (Shannon-Wiener diversity index calculated for total data), (C) sponge species richness (total no. of species), and (D) sponge species diversity (ShannonWiener diversity index calculated for total data) with depth and surface inclination (inclined, vertical, horizontal) at 2 sites in Indonesia 
Table 2. Percentage abundance of different sponge morphologies (combined over surface angles) at 2 sites in SE Sulawesi, Indonesia. Bold print indicates those morphologies that characterised each site. A classification scheme of proposed functional roles and adaptive significance of sponge morphologies reported from SE Sulawesi. (A) Proposed primary function roles: $1=$ filtering/nutrient recycling, $2=$ reef consolidators/stabilisers, $3=$ major spatial competitors, $4=$ disruptors of near-substratum water flow regimes, $5=$ bio-eroders, $6=$ microhabitat providers, $7=$ primary production. (B) Proposed adaptive significance: $1=$ predator deterrence, 2 = predator avoidance, 3 = prevention of sediment settlement, $4=$ trapping of sediment, $5=$ competitive advantage, $6=$ enhanced area exposed to light (for symbionts), $7=$ high wave action/current flow/reduced drag, $8=$ entrained/ enhanced water flow, 9 = flexibility. See Table 1 for the sponge families that exhibit each morphology

\begin{tabular}{|c|c|c|c|c|c|c|c|c|c|}
\hline Morphology & $\begin{array}{l}\text { Sampela } \\
\text { reef crest } \\
(\mathrm{n}=301)\end{array}$ & $\begin{array}{l}\text { Sampela } \\
5 \mathrm{~m} \\
(\mathrm{n}=140)\end{array}$ & $\begin{array}{c}\text { Sampela } \\
10 \mathrm{~m} \\
(\mathrm{n}=138)\end{array}$ & $\begin{array}{l}\text { Hoga } \\
\text { reef crest } \\
(\mathrm{n}=70)\end{array}$ & $\begin{array}{c}\text { Hoga } \\
5 \mathrm{~m} \\
(\mathrm{n}=95)\end{array}$ & $\begin{array}{c}\text { Hoga } \\
10 \mathrm{~m} \\
(\mathrm{n}=84)\end{array}$ & $\begin{array}{c}\text { Hoga } \\
15 \mathrm{~m} \\
(\mathrm{n}=80)\end{array}$ & $\begin{array}{l}\text { (A) Proposed } \\
\text { functional } \\
\text { roles }\end{array}$ & $\begin{array}{l}\text { (B) Proposed } \\
\text { adaptive } \\
\text { significance }\end{array}$ \\
\hline 1) Barrel & 0 & 0 & 1 & 0 & 0 & 1 & 0 & $1,4,5,7$ & 7 \\
\hline 2) Branched multiplate & 0 & 0 & 0 & 0 & 1 & 1 & 1 & 1,4 & 5,7 \\
\hline 3) Boring & 0 & 0 & 0 & 0 & 0 & 0 & 1 & 1,5 & 2 \\
\hline 4) Clathrate & 0 & 0 & 1 & 0 & 1 & 1 & 2 & $1,2,3$ & 7 \\
\hline 5) Conulose infundibuliform & 0 & 0 & 0 & 0 & 0 & 0 & 1 & 1,4 & 1,3 \\
\hline 6) Cushions & 0 & 4 & 9 & 0 & 24 & 21 & 25 & $1,2,3$ & 5,7 \\
\hline 7) Cup & 0 & 0 & 0 & 0 & 0 & 1 & 0 & 1,4 & 3,7 \\
\hline 8) Dome & 0 & 0 & 0 & 0 & 0 & 1 & 2 & 1 & 3,7, \\
\hline 9) Fistulate & 0 & 4 & 8 & 0 & 0 & 1 & 1 & $1,2,3$ & 5,7 \\
\hline 10) Flagelliform & 0 & 1 & 1 & 0 & 0 & 1 & 0 & 1,4 & 3,9 \\
\hline 11) Flabellate & 0 & 0 & 0 & 0 & 1 & 0 & 0 & 1,4 & 7,9 \\
\hline 12) Flake & 86 & 27 & 25 & 68 & 21 & 12 & 25 & $1,2,3,7$ & $5,6,7$ \\
\hline 13) Flake-digitate & 12 & 9 & 0 & 28 & 3 & 1 & 1 & $1,2,3,7$ & $3,5,6,8$ \\
\hline 14) Infundibuliform & 0 & 0 & 1 & 0 & 0 & 0 & 0 & 1 & $3,7,8$ \\
\hline 15) Globulose & 0 & 1 & 1 & 0 & 1 & 2 & 1 & 1,4 & 6 \\
\hline 16) Horizontal plates & 1 & 0 & 1 & 0 & 2 & 0 & 0 & 1 & 3,8 \\
\hline 17) Massive chimneys & 0 & 1 & 0 & 0 & 1 & 1 & 1 & $1,4,5,6$ & 3,8 \\
\hline 18) Massive crust & 1 & 1 & 3 & 0 & 8 & 7 & 7 & $1,2,3$ & $7,6,7$ \\
\hline 19) Massive crust-raised oscu & ules 0 & 1 & 0 & 0 & 0 & 1 & 1 & $1,2,3$ & $9,7,6$ \\
\hline 20) Massive peduculate & 0 & 0 & 0 & 0 & 1 & 0 & 0 & $1,4,6$ & 3,8 \\
\hline 21) Massive plate & 0 & 0 & 1 & 0 & 0 & 0 & 1 & $1,4,6$ & 6 \\
\hline 22) Massive conulose & 0 & 1 & 0 & 0 & 1 & 1 & 1 & $1,2,3$ & $1,4,7$ \\
\hline 23) Massive tube & 0 & 0 & 1 & 0 & 0 & 0 & 0 & $1,4,6$ & $3,7,8$ \\
\hline 24) Massive upright & 0 & 0 & 4 & 0 & 0 & 2 & 2 & $1,4,6$ & 8 \\
\hline 25) Mini peduculate & 0 & 0 & 1 & 0 & 0 & 0 & 0 & 1,6 & 3,8 \\
\hline 26) Mini tubes & 0 & 0 & 1 & 0 & 0 & 0 & 0 & 1 & 8,3 \\
\hline 27) Multi-fat branch & 0 & 2 & 1 & 0 & 1 & 1 & 0 & 1,4 & 3 \\
\hline 28) Multi-orientation plates & 0 & 1 & 1 & 0 & 0 & 0 & 0 & 1,4 & 6,9 \\
\hline 29) Multi-thin branch & 0 & 0 & 0 & 0 & 1 & 0 & 0 & 1,4 & 3,9 \\
\hline 30) Oval & 0 & 0 & 0 & 0 & 0 & 1 & 0 & $1,4,6$ & 8,3 \\
\hline 31) Oval-supported & 0 & 0 & 0 & 0 & 0 & 0 & 1 & $1,4,6$ & 8,3 \\
\hline 32) Papillate & 0 & 1 & 2 & 0 & 0 & 1 & 0 & $1,2,3$ & 8,7 \\
\hline 33) Reverse ficiform & 0 & 0 & 1 & 0 & 0 & 0 & 0 & 1,4 & 8,3 \\
\hline 34) Repent & 0 & 2 & 1 & 0 & 2 & 2 & 3 & $1,2,3$ & 5,7 \\
\hline 35) Repent-arborescent & 0 & 0 & 0 & 0 & 0 & 0 & 1 & $1,2,3,4$ & 7,9 \\
\hline 36) Single branch & 0 & 0 & 3 & 0 & 1 & 1 & 2 & 1,4 & 3,7 \\
\hline 37) Stalked ficiform & 0 & 0 & 0 & 0 & 2 & 0 & 1 & 1,4 & 9,8 \\
\hline 38) Thin encrusting & 0 & 44 & 32 & 4 & 22 & 39 & 18 & $1,2,3$ & $5,6,7$ \\
\hline 39) Thin encrusting conulose & 0 & 0 & 0 & 0 & 1 & 0 & 1 & $1,2,3,7$ & $1,4,5,6,7$ \\
\hline
\end{tabular}

little difference between sites, but did uncover changes with depth (Table 3). Functional diversity on the reef crest was lower at both sites and most sponges were considered to be major spatial competitors and reef consolidators/stabilisers, with a large proportion of sponges at both sites and all depths fulfilling these roles. Higher proportions of sponges fulfilled the remaining functional roles as depth increased at both sites. Shannon-Wiener functional diversity values (calculated across surface angles) showed little difference between sites for any given depth; however, a consistent, but small, increase in FD with depth was evident at both sites (Table 3).

\section{Assemblage species, morphological and functional composition}

Even though univariate comparisons of SD, MD and FD showed little difference between sites, notable dif- 
Table 3. Percentage of sponges fulfilling different functional roles and functional diversity $\left(H^{\prime}\right)$ on 2 coral reefs. $\mathrm{H}=\mathrm{Hoga}$, $\mathrm{S}=$ Sampela, $\mathrm{RC}=$ reef crest (averaged across surface angle)

\begin{tabular}{|c|c|c|c|c|c|c|c|}
\hline Functional role & S RC & $\mathrm{S} 5 \mathrm{~m}$ & $\mathrm{~S} 10 \mathrm{~m}$ & $\mathrm{HRC}$ & $\mathrm{H} 5 \mathrm{~m}$ & $\mathrm{H} 10 \mathrm{~m}$ & $\mathrm{H} 15 \mathrm{~m}$ \\
\hline Filtering/nutrient recycling & 100 & 100 & 100 & 100 & 100 & 100 & 100 \\
\hline Reef consolidators/stabilisers & 98 & 94 & 82 & 96 & 80 & 88 & 86 \\
\hline Major spatial competitor & 98 & 90 & 80 & 96 & 80 & 86 & 86 \\
\hline Disruption of near-substratum flow & 1 & 6 & 16 & 0 & 8 & 12 & 12 \\
\hline Bio-erosion & 1 & 1 & 1 & 0 & 1 & 2 & 2 \\
\hline Microhabitat & 0 & 2 & 7 & 0 & 2 & 3 & 5 \\
\hline Primary production & 98 & 36 & 26 & 96 & 25 & 14 & 27 \\
\hline Diversity $\left(H^{\prime}\right)$ & 1.42 & 1.44 & 1.53 & 1.39 & 1.43 & 1.43 & 1.45 \\
\hline
\end{tabular}
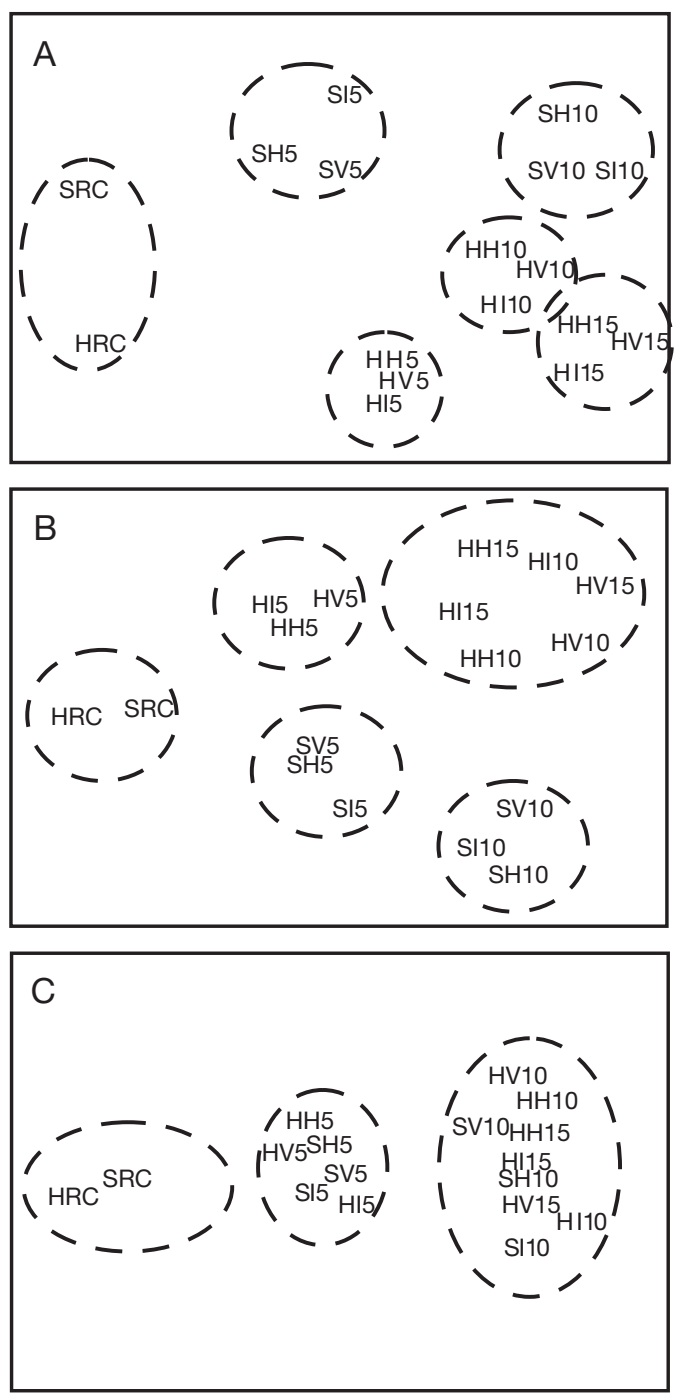

Fig. 2. Non-metric multi-dimensional scaling (nMDS) plots of (A) sponge morphological, (B) species and (C) functional assemblage composition at different depths at Sampela (S) and Hoga $(\mathrm{H})$ on vertical (V), inclined (I) and horizontal (H) surfaces (codes represent site, inclination and depth respectively; $\mathrm{RC}=$ reef crest). Dotted lines highlight separation among sponge assemblages at different depths at Sampela and Hoga. Stress for each plot $<0.09$ ferences were identified in assemblage compositions from the results of MDS for species and morphological data (Fig. 2). There was clear separation of the species and morphological assemblages at Sampela and Hoga, and it was possible to identify assemblage structure based on depth for these 2 assemblage parameters, even though little difference was observed among benthic surface angles (for any given depth). When the nMDS results for sponge MC and SC were compared, the patterns found for each data set were very similar (Fig. 2); however, there was greater assemblage structure for the morphological data, with further separation of the 10 and $15 \mathrm{~m}$ assemblages than seen for species data. Despite this difference a significant correlation (Spearman's $r_{S}$ 0.80, p $<0.001,100000$ permutations) was found when the RELATE function (in PRIMER) was used to compare the similarity matrices used to create the nMDS plots for species and morphology data, meaning that similar matrices were produced for species and morphological data. The patterns reported for species and morphological data contrasted with those for FC data, where no differences were apparent between the 2 sites and only depth structured the assemblage (Fig. 2). No significant correlations (using RELATE, Spearman's $\mathrm{r}_{\mathrm{S}}<0.34, \mathrm{p}>$ 0.05, 100000 permutations) were reported for comparisons between similarity matrices produced for FC data and either SC or MC data.

\section{DISC USSION}

\section{Correlating species, morphological and functional diversity}

Importantly, this study is the first to demonstrate that although marine assemblage SD and FD may correlate for univariate measures, the $\mathrm{FC}$ of an assemblage or community may not correlate with SC, which has important conservation and management implications with respect to maintaining ecosystem functioning. Environmental managers need to be aware of the factors control- 
ling both SC and FC to ensure the protection of both biodiversity and ecosystem functioning. This study has shown little difference in the proportion of sponges fulfilling the different functional roles or in the FC of sponge assemblages between reefs experiencing different sedimentation levels; nevertheless, changes were evident with depth (e.g. sponges involved in primary production decreased with depth). Univariate patterns of FD were found to reflect those of SD and MD, supporting studies correlating SD and FD (e.g. Micheli \& Halpern 2005); however, FC patterns contrasted with both species and morphological data. These results support the rejection of all 3 hypotheses and demonstrate that sedimentation is not as important in influencing the FC of sponge assemblages as it is for the $\mathrm{SC}$ and $\mathrm{MC}$, and that other depth-related factors are more important (excluding sedimentation). Such factors might include light availability, competitor/predator differences, food availability or wave action influences, all of which are known to influence sponge assemblages.

\section{Environmental restriction of functional roles}

Although it is possible to hypothesise adaptive significance for the majority of sponge morphologies (Table 3), experimental/observational evidence is lacking in most cases (but see Bidder 1923, Bell et al. 2003, Bell 2004). Table 2 shows a proposed scheme for the adaptive significance of the various sponge morphologies reported in this study, based on the available literature (not only restricted to sponge morphologies). Few sponge morphologies were restricted exclusively to any specific site or depth, and those that were exclusive were generally present at a low abundance. The main exception was on the reef flat, where most sponge morphologies were excluded except lowprofile forms. These low-profile forms consisted mainly of encrusting flake forms, which were mostly Dysidea herbacea, a primary producer (Borowitska et al. 1989). This form decreased in abundance with depth, which was probably due to a reduction in light availability for its symbionts. Generally, there was little evidence to suggest that specific functional roles associated with particular sponge morphologies were restricted to any particular environmental regime, which contrasts with temperate regions where certain morphologies dominate different environments with different physical characteristics (Bell \& Barnes 2000a).

\section{Species, morphological and functional diversity}

Differences were observed in morphological and species richness and diversity with increasing depth (and sedimentation) at both sites, but not between sites or among surface angles (for any specific depth interval), which was consistent with the changes in FD with depth. Richness for all 3 measures was low on the reef crest and only low-profile forms were found, showing limited functionality of sponges. Wave action is greatest on the reef crest, and this environmental pressure is probably responsible for the low morphological richness, because upright morphologies are unlikely to be suited to high energy environments owing to small basal attachment areas relative to their overall biomass (Bell \& Barnes 2000b). The domination of reef surfaces - particularly on the reef crest-by encrusting forms may also be an adaptation to maximise surface area for species dependent on photosynthetic symbionts (Wilkinson 1987, Cheshire \& Wilkinson 1991). For example, the encrusting flake form of Dysidea herbacea was particularly abundant on the reef crest at Sampela, where spatial competition is reduced because of low hard coral abundance and wave action (Bell \& Smith 2004). These low-profile morphologies have a greater surface area to body mass ratio than other upright or massive forms, thereby enabling more symbionts to be exposed to the light. As depth increases the influence of wave action decreases, and upright (often inflexible), 3-dimensional forms were found to increase in abundance. No major differences were seen among surface angles, which is inconsistent with previous studies of temperate sponge assemblages, where differences in the sponge assemblage (based on species and morphology data) were observed among surface angles and attributed to differences in sedimentation, light and competition effects (Bell \& Barnes 2000b)

The sponge species richness in this small area of Indonesia is very high compared with other studies of tropical and temperate regions. For example, for studies conducted at sampling areas of similar size to that of the present study in Mozambique, Cuba and Ireland, sponge species richness was reported as 73, 77, 80 respectively (Bell \& Barnes 2000b). As well as being very species rich, the sponge assemblages in the Wakatobi are also morphologically rich, but the majority of morphologies described were rare, with thin encrusting, flakes and flake-digitate types dominating. The abundance of these lowprofile, essentially encrusting forms is consistent with previous studies of reef fauna (Vacelet \& Vasseur 1977, Bell \& Smith 2004), but is perhaps surprising as a feature of coral reefs in general, given that space is considered a limiting factor and these morphologies require more space per unit body mass than other morphologies that grow away from the substratum. 


\section{Functional assessment of sponge assemblages}

In addition to the functional roles discussed here, sponges may also have further roles not quantified in the present study. Sponges form symbiotic relationships with many photosynthetic organisms, but also with bacteria that may comprise up to $40 \%$ of the sponge (Corredor et al. 1988). These bacteria are considered important in transforming organically bound nutrients (particulate and organic material) into inorganic nutrients and may play an important role in reef productivity. Symbiotic associations may also play an important role in sponge nitrogen flux (Davy et al. 2002) and make a significant contribution to the nitrogen required for reef productivity (Corredor et al. 1988). Sponges may also act as a source of nutrition to a range of reef predators, including parrot fish and nudibranchs (Dunlap \& Pawlik 1996). It is currently unclear how dependent these functional roles will be on sponge morphologies and whether they can be included in the functional classification scheme described in the present study.

There has been some debate over the degree of functional redundancy in marine systems, with at least one study suggesting low functional redundancy in marine assemblages (Micheli \& Halpern 2005). Such conclusions may, in part, be a result of the scale of assessment of functional traits. For example, if trophic status is used as a classifying mechanism, then most sponges would be classified as sessile planktivorous invertebrates (see Micheli \& Halpern 2005), which is clearly not representative of the complex roles sponges perform, and an assessment based on biological traits may be more appropriate (see Bremner et al. 2003). When biological traits are used for functional assessments, care must be taken to ensure there is ecological significance associated with the categories used. Despite this, there is a high degree of functional redundancy within sponge assemblages for some functional groups (e.g. changing near substratum flow regimes and filtering/nutrient recycling); however, reef bio-erosion was undertaken by only a few species of one particular morphology. Such roles performed by only a few species are of particular interest because their removal is likely to cause major changes to ecosystem functioning (Petchey 2000). It is surprising that $\mathrm{MC}$ and $\mathrm{FC}$ did not correlate (given that FC was estimated from MC), but this is accounted for by the high degree of functional redundancy among sponge morphologies. In the present study each of the functional traits assigned to sponges were given equal weighting (for discussion on weighting traits see Petchey \& Gaston 2006), but some are likely to be more important than others. Ranking the ecological significance of different functional traits, not only for sponges, is likely to be difficult and remains a potential source of error in functional diversity studies. Understanding the interactions between functional traits and the loss of FD on ecosystem functioning remains a challenging area of ecological research.

Acknowledgements. I thank Operation Wallacea and the staff of the Hoga Island Marine Research Station for providing financial and logistical support, respectively, for fieldwork. I am also grateful to Sebastian Hennige for help with PAM Fluorometry.

\section{LITERATURE CITED}

Aerts LAM, van Soest RWM (1997) Quantification of spongecoral interactions in a physically stressed reef community, NE Colombia. Mar Ecol Prog Ser 148:125-134

Alcolado PM (1990) General features of Cuban sponge communities. In: Rützler K (ed) New perspectives in sponge biology. Smithsonian Institute Press, London, p 351-357

Barnes DKA (1999) High diversity of tropical intertidal zone sponges in temperature, salinity and current extremes. Afr J Ecol 37:424-434

Barnes DKA, Bell JJ (2002) Coastal sponge communities of the West Indian Ocean: morphological richness and diversity. Afr J Ecol 40:350-359

Bell JJ (2004) Adaptation of a tubular sponge to sediment habitats. Mar Biol 146:29-38

Bell JJ, Barnes DKA (2000a) The influence of bathymetry and flow regime upon the morphology of sublittoral sponge communities. J Mar Biol Assoc UK 80:707-718

Bell JJ, Barnes DKA (2000b) A sponge diversity centre within a marine island. Hydrobiologia 440:55-64

Bell JJ, Barnes DKA (2001) The use of sponge morphological diversity as a qualitative predictor of species diversity. Aquat Conserv 11:109-121

Bell JJ, Barnes DKA (2002) Modelling sponges species diversity using morphological predictor: a tropical test of temperate model. J Nat Conserv 10:41-50

Bell JJ, Barnes DKA (2003) The importance of competitor identity, morphology and ranking methodology to outcomes in interference competition between sponges. Mar Biol 143:415-426

Bell JJ, Smith DJ (2004) Ecology of sponges (Porifera) in the Wakatobi region, south-eastern Sulawesi, Indonesia: richness and abundance. J Mar Biol Assoc UK 84:581-591

Bell JJ, Barnes DKA, Turner JR (2002) The importance of micro and macro morphological variation in the adaptation of a sublittoral demosponge to current extremes. Mar Biol 140:75-81

Bell JJ, Barnes DKA, Shaw C (2003) Branching dynamics of two species of arborescent demosponge: effect of flow regime and bathymetry. J Mar Biol Assoc UK 82:279-294

Bell JJ, Burton M, Bullimore B, Newman PB, Lock K (2006) Morphological monitoring of proiferan assemblages: a potential solution for monitoring large-scale Marine Protected Areas (MPAs) or Special Areas of Conservation (SAC). Mar Ecol Prog Ser 311:79-91

Bidder GP (1923) The relation of the form of a sponge to its current. Q J Microsc Sci 67:293-323

Borowitska MA, Hinde R, Pironet F (1989) Carbon fixation by the sponge Dysidea herbacea and its endosymbiont Oscillatoria spongeliae. In: Choat $\mathrm{JH}$, Barnes D, Borowitzka 
MA, Coll JC and 14 others (eds) Proc 6th Int Coral Reef Symp, Townsville 3:151-156

Bremner J, Rogers SI, Frid CLJ (2003) Assessing functional diversity in marine benthic ecosystems: a comparison of approaches. Mar Ecol Prog Ser 254:11-25

Burton M (1947) The significance of size in sponges. Annu Mag Nat Hist 14:216-220

Carballo JL (2006) Effect of natural sedimentation on the structure of tropical rocky sponge assemblages. Ecoscience 13:119-130

Cheshire AC, Wilkinson CR (1991) Modelling the photosynthetic by sponges on Davies Reef, Great Barrier Reef. Mar Biol 109:13-18

Corredor JE, Wilkinson CR, Vicente VP, Morell JM, Otero E (1988) Nitrate release by Caribbean reef sponges. Limnol Oceanogr 33:114-120

Davy SK, Trautman DA, Borowitzka MA, Hinde R (2002) Ammonium excretion by a symbiotic sponge supplies the nitrogen requirements of its rhodophyte partner. J Exp Biol 205:3505-3511

Dayton PK (1978) Observations of growth, dispersal and population dynamics of some sponges in McMurdo Sound, Antarctica. In: Levi C, Boury-Esnault N (eds) Sponge biology. Colloq Int CNRS 291:271-282

Dayton PK, Robilliard GA, Paine RT, Dayton LB (1974) Biological accommodation in the benthic community at McMurdo Sound, Antarctica. Ecol Monogr 44:105-128

Dunlap M, Pawlik JR (1996) Video-monitored predation by Caribbean reef fishes on an array of mangrove and reef sponges. Mar Biol 126:117-123

Hiscock K (1983) Water movement. In: Earll R, Erwin DG (eds) Sublittoral ecology. The ecology of the shallow sublittoral benthos. Clarendon Press, Oxford, p 58-96

Micheli F, Halpern BS (2005) Low functional redundancy in coastal marine assemblages. Ecol Lett 8:391-400

Naeem S (2002) Autotrophic-heterotrophic interactions and their impacts on biodiversity and ecosystem functioning. In: Kinzig AP, Pacala SW, Tilman D (eds) The functional consequences of biodiversity. Princeton University Press, Princeton, NJ, p 120-150

Okamura B (1985) The effects of ambient flow velocity, colony

Editorial responsibility: Roger Hughes (Contributing Editor), Bangor, UK size, and upstream colonies on the feeding success of Bryozoa. II. Conopeum reticulum (Linnaeus), an encrusting species. J Exp Mar Biol Ecol 89:81-96

Palumbi SR (1984) Tactics of acclimation: morphological changes of sponges in an unpredictable environment. Science 225:1478-1480

Pang RK (1973) The ecology of some Jamaican excavating sponges. Bull Mar Sci 23:227-243

Petchey OL (2000) Species diversity, species extinctions, and ecosystem function. Am Nat 155:696-702

Petchey OL, Gaston KJ (2002a) Extinction and the loss of functional diversity. Proc R Soc Lond B 269:1721-1727

Petchey OL, Gaston KJ (2002b) Functional diversity (FD), species richness and community composition. Ecol Lett 5: 402-411

Petchey OL, Gaston KJ (2006) Functional diversity: back to basics and looking forward. Ecol Lett 9:741-758

Reiswig HM (1971) In situ pumping activities of tropical Demospongiae. Mar Biol 9:38-50

Rützler K (1975) The role of burrowing sponges in bioerosion. Oecologia 19:203-219

Schmahl GP (1990) Community structure and ecology of sponges associated with four southern Florida coral reefs. In: Rützler K (ed) New perspectives in sponge biology. Smithsonian Institute Press, London, p 376-383

Steele JH (1991) Marine functional diversity. Bioscience 41: $470-474$

Vacelet J, Vasseur P (1977) Sponge distribution in coral reefs and related areas in the vicinity of Tulear (Madagascar). Proc 3rd Int Coral Reef Symp 3:113-121

Wilkinson CR (1987) Productivity and abundance of large sponge populations on Flinders Reef Flats, Coral Sea. Coral Reefs 5:183-188

Wulff JL (1995) Effects of a hurricane on survival and orientation of large erect coral reef sponges. Coral Reefs 14:55-61

Wulff JL (2001) Assessing and monitoring coral reef sponges: why and how? Bull Mar Sci 69:831-846

Wulff JL (2006) Ecological interactions of marine sponges. Can J Zool 84:146-166

Wulff JL, Buss LW (1979) Do sponges help to hold coral reef together? Nature 281:474-475

Submitted: September 13, 2005; Accepted: December 11, 2006 Proofs received from author(s): May 24, 2007 